two choices: he can adopt an elementary approach, and is then liable to provide no more information than can be found in a student's textbook, or he can aim at comprehensiveness and run the risk of producing a mere catalogue of diseases. Almost all the remaining 11 chapters have suffered because their authors have been obliged to range too widely. For example, Savin is allowed 11 pages (less the space occupied by 8 halftones) to cover all infections and infestations. It is greatly to his credit that the chapter is readable and informative, but it would have been far more so had he been asked to cover only one disease, or a small group of related diseases.

Most chapters have adequate up-to-date references, but one gives no references whatever, and some give few that are recent. In view of the wide readership to which this book is addressed, it would have been helpful had each author listed one or two standard monographs for the guidance of his nondermatologist readers. For example, the chapter on 'The newborn' could have drawn attention to Solomon and Esterly's Neonatal dermatology (1973), of which a new edition is in preparation.

Despite these weaknesses, this book does indeed contain something of interest to all who are concerned with the treatment of skin diseases in children.

\section{ARTHUR ROOK}

The Prevalence of Illness in Childhood. A report of the British Births Child Study on illnesses and hospital experiences of children during the first three-and-ahalf years of life. By $\mathbf{R} \mathbf{N}$ Chamberlain and R N Simpson. (Pp. 142; illustrated + tables. $£ 15.00$ hardback.) Pitman Medical: Tunbridge Wells. 1979.

This monograph is based on the British Births Child Study, and records some of the important medical conditions and events in a sample of the children born in April 1970 and followed to age $3 \frac{1}{2}$ years. Information is given on their hospital experiences and on the incidence or prevalence of, for example, congenital malformation, infective diseases, respiratory disorders, convulsions, and accidents. Some striking facts emergehalf the children had attended hospital as out- or inpatients, and $20 \%$ had had hospital admissions. About $30 \%$ had had accidents for which hospital attention was sought.
The book is a mine of information for paediatricians interested in knowing how often the disorders they see occur in the child population at large. I found it of great value in supplementing and bringing up to date an introductory lecture to students starting their paediatric course.

However, paediatricians may have some doubts about the study which only an epidemiologist can answer. Cohort studies are time-consuming and difficult; the authors have described the difficulties with a degree of detail and honesty which sometimes makes the simple figures on prevalence hard to extract. Here are some of the problems. The original study was based on all 16955 babies born alive in the UK in one week in April 1970. From these a random $10 \%$ sample was selected for follow-up, and the children of single mothers were then excluded 'because of the difficulties involved in tracing and examining them'. The sample followed therefore consisted of 1609 children. The authors admit that this is a small one for ascertaining the frequency of rare conditions; but actually the numbers of children it produces even with relatively common conditions are not impressive. Thus hypospadias detectable at birth seems to have vanished. There were 41 children with febrile convulsions suggesting (with some ifs and buts) an incidence of $3.7 \%$. This figure corresponds well with that from other studies, but the total number is far too small to analyse much further, in the way that has been done so fruitfully with the 1706 children from the American Collaborative Project who had febrile convulsions and were followed to age 7 .

I had greater worries over the nature of the sample, the completeness of the follow-up, and the methods of collecting information. Children of single mothers constitute a wholly disproportionate volume of the work of a paediatric department, especially in an inner city area, and their exclusion from the sample must bias the findings. The information in the study is based on examinations (and histories) made at ages 2 and $3 \frac{1}{2}$, but for each of these examinations only about $70 \%$ of the children were available. Finally, much of the information is based on what the mothers remembered of their children's illnesses, and this information must be more accurate for some illnessesand some mothers-than for others. With these uncertainties, one cannot help doubting the validity of findings which seem quite unexpected-such as that social class seems to have little effect on the incidence of respiratory disorders or of accidents (although children of working mothers were much more prone to accidents).

However, there is much in this book to interest the paediatrician, particularly the community paediatrician. It will be the starting point for many wishing to know or to study the prevalence of disorders of young children.

ROGER ROBINSON

A System of Newborn Physicial Examination. By $J$ W Scanlon, $T$ Nelson, L J Grylack, and Y F Smith. (Pp. 96; illustrated + tables. $£ 5.50$ paperback.) MTP Press: Lancaster. 1979.

This book is an account of the authors' idiosyncratic approach to the examination of a newborn infant. Nine chapters describe the examination of particular parts of the body, including a whole chapter on the eye. There are further chapters on gestational age assessment, examination in the delivery room, and behavioural evaluation.

Although the authors are presumably not attempting to describe the examination of the ill infant-for example, the early and subtle signs of severe disseminated infection or meningitis are not mentioned -it is virtually impossible to describe some physical signs, such as oedema or hepatosplenamegaly, without alluding to signs of disease. This causes uneveness in emphasis-why mention broken bones and the signs thereof without discussing osteomyelitis or arthritis? Why mention epispadias without torsion of the testicle? It also limits the value of the book to medical staff who do, after all, have to examine sick neonates as well as healthy ones.

Provided that it is the normal neonate that is being examined, the descriptions are unnecessarily detailed for the houseman or resident doing routine neonatal examinations. What practising neonatologist really spends 10 minutes doing a normal neonatal examination, including 5 minutes for a fundoscopy? Is such a complex gestational assessment score necessary, particularly when much simpler and equally accurate ones exist? Do we really need yet another set of neonatal behaviour scores of dubious prognostic value? Is it really necessary to examine the 
chest in detail in a normal baby; I doubt if I have detected physical signs in the chest of an asymptomatic infant.

For those doing normal examinations the book lacks direction about what parts are really important-namely, dislocated hips, congenital heart disease, or cataracts - which will not have been obvious to the mother who will have already been over the child with a fine tooth comb-but which nevertheless require treatment. It is particularly sad that it is not stated that such examinations should be done with the mother present.

There are several small irritating inaccuracies or inconsistencies. In chapter 6 the red blotches at the nape and the glabella are described as haemangiomata, yet this aetiology is denied in chapter 8 . The harlequin colour change is not dependent lividity; acrocyanosis is not cyanosis of the face and scalp.

Although the book contains much useful information, the inaccuracies and lack of direction make it unsuitable as an introduction to normal neonatal examination, and there is insufficient data for it to be of value for those caring for the sick infant.

N R C ROBERTON

Understanding ECGs in Infants and Children, second edition. By L C Harris and Ellen Feinstein. (Pp. 109; illustrated + tables. $\$ 12.50$ paperback.) Little Brown: Boston. 1979.

Although this book is written exclusively about electrocardiograms in infants and children, the authors begin by explaining the basic principles of electrocardiography. The explanation of the calculation of the axis of the electrocardiogram -so useful in paediatric cardiologyis clear and well illustrated. There are many examples and tests so that the reader can be certain he has understood the lesson. The vector approach is likewise carefully described with many clear illustrations. I found the practice of phrasing the questions in multiple choice format irritating and unnecessary; it would have been better to use the space to allow ECG tracings, and comments relevant to them, to appear on the same page.

The typical ECG records in the common simple congenital heart lesions are shown and the criteria for right and left ventricular hypertrophy are listed. The tables at the end of the book give normal standards for infants and children up to 16 years. There is also a good section on dysrhythmias and ECG changes in electrolyte disorders, once again with many examples of tracings.

It is a pity that the clear diagram of an ECG complex at the beginning has the S-T segment wrongly labelled and that the final test for the reader at the end of the book has an illustration of WolffParkinson-White syndrome type B labelled as type A. Small points, but worrying to the reader.

This book is particularly suitable for house officers and paediatricians in training. They will not find a clearer or better illustrated text on children's electrocardiograms.

o SCOTT

\section{Shorter notices}

Multiple Choice Questions on Paediatrics. By Roy Meadow. (Pp. 60. $£ 1.90$ paperback.) Blackwell Scientific: Oxford. 1979.

A useful little paperback containing 175 multiple choice questions and 12 brief case histories with questions on diagnosis and management. The MCQs are well constructed and in the form familiar to most British examinees, and there is unusually little to quarrel with in the content or answers. Helpful to the potential examiner or examinee; but also of some genuine educational value to the student learning or revising paediatrics.

Paediatric Orthopaedics and Fractures, second edition, in two volumes. By W J W Sharrard. (Pp. vol. 1, 740; vol. 2, 922; both with index. Illustrated + tables.
$£ 70.00$ for the two volumes, hardback. $\rho^{.}$ Blackwell Scientific: Oxford. 1979.

In the 8 years since this work was firs? published, the number of pages haso increased by half, it now appears in two $\overline{\bar{\gamma}}$ volumes, and the cost has risen more than 4-fold. The whole subject of paediatric orthopaedic surgery and orthopaedies trauma is still covered by one surgeon $\overrightarrow{0}$ The increase in content is to bring the problems of paediatric orthopaedic sur $\vec{\omega}$ gery up to date and to increase the use? fulness of the text by giving more details of operative techniques. Moreover, by extending the list of references and ther illustrations, the value of the volumes hassbeen increased by making the catalogue of diseases, and the literature about them more complete. Sharrard has maintained the high standard set in the first edition. The standard of presentation and the care with updating the material wile ensure that this edition will be one of the standard books of reference fo orthopaedic surgeons and those in training, and that future editions will bछ awaited with pleasure.

A Scheme of Paediatric Neurologica Investigation. By Nicholas Cavanagho (Pp. 48; paperback.) Obtainable free of charge from Geigy Pharmaceuticals? Wimblehurst Road, Horsham, Wes $\vec{E}$ Sussex RH12 4AB. 1979.

A small, attractively produced bookle listing the investigations worth considering. in children with common neurologicap problems such as fits, mental subnor? mality, and acute encephalopathy. Based on practice at The Hospital for Sick Children, Great Ormond Street. Notes explain the reasons for the tests where these are not obvious. Because tests which may rarely be relevant, as well as mandatory ones, are included, the lis must be used with discretion to avoidE. investigatory excesses. The reader must also note that certain specified problems are not covered. A very useful compila tion, of value to the paediatric seniot house officer and his seniors. 